\title{
Endothelial Progenitor Cells: Characterization and Role in Cerebral Arteriovenous Malformation
}

\author{
Nida Fatima ${ }^{1}$, Ashfaq Shuaib ${ }^{2}$ and Maher Saqqur ${ }^{2}$ \\ ${ }^{1}$ Visiting Instructor Neurosurgery, Stanford University School of Medicine, USA \\ ${ }^{2}$ Senior Consultant Neurology, University of Alberta, Canada
}

*Corresponding author: Nida Fatima, Visiting Instructor Neurosurgery, Stanford University School of Medicine, USA

To Cite This Article: Nida Fatima. Endothelial Progenitor Cells: Characterization and Role in Cerebral Arteriovenous Malformation. Am J Biomed Sci \& Res. 2019 - 3(4). AJBSR.MS.ID.000697. DOI: 10.34297/AJBSR.2019.03.000697

Received: June 20, 2019 | Published: June 27, 2019

\begin{abstract}
Background: The angiogenesis in Cerebral Arteriovenous malformations (cAVMs) may occur through activation of chemokines [stromal-cell derived factor-1 (SDF-1)], which ultimately recruit endothelial progenitor cells (EPCs) for aberrant neovascularization. Thus, we determined the role of EPCs in the vasculogenesis of cAVMs.

Methods: Literature search was made through electronic database on "PubMed", "EMBASE", "Google Scholar", and "Science Direct" from 19902019 using MeSH headings of "Endothelial Progenitor Cells", "Arteriovenous Malformation", and "Stromal-cell derived factor-1 (SDF-1)" using Boolean operator "and" /"or". The inclusion criterion included human experimental studies on EPCs in the cAVMs.

Results: Histo morphological characteristics of vasculogenesis, both quantitatively and qualitatively, are pivotal in determining the prognosis of patients with AVMs. cAVMs patients have higher expression of markers of EPCs precursors, which is characterized by stem cell (CD133), endothelial (VEGF-2, CD31, and/or VE-cadherin), and hematopoietic cell markers (CD31). The SDF-1 was co-expressed with CD31+, predominantly on the endothelium of the vessel wall, and recruit ECPs from the peripheral cells to the target tissues thus leads to active remodeling and angiogenesis. A positive correlation exists between the VEGF- A ( $\mathrm{r}=0.53)$ or HIF-1 $\alpha(\mathrm{r}=0.43)$ and SDF-1 $\alpha$.
\end{abstract}

Conclusion: The EPCs plays an important role in the vasculogenesis of cAVMs lesions through activation by SDF-1/CXCR4 pathway. Therefore, further experimental studies are needed to formulate a therapy targeting these EPCs in the management of patients with cAVMs.

Keywords: Arteriovenous Malformations; Endothelial cell; Precursor cells

\section{Introduction}

Cerebral Arteriovenous malformations (cAVMs) are characterized by "nidus", which is a group of abnormally dilated blood vessels, due to aberrant angiogenesis and vascular re modeling [1]. Histopathological and molecular analysis of these CAVMs revealed higher level of angiogenic factors and vascular cytokines of the cAVMs $[2,3]$. Concentrated effects of angiogenic and inflammatory factors, which include angiopoietin-2, matrix metalloproteinase (MMP)-9, vascular endothelial growth factors (VEGF), and IL-6 contribute towards maintaining the angiogenic phenotype of the cAVMs $[4,5]$.

Endothelial progenitor cells (EPCs), derived from bone marrow, plays an indispensable role in initiating and promoting abnormal tumor vasculogenesis by either secreting paracrine factors or by incorporating directly into the vasculature [6,7]. Stromal cell derived factor-1 (SDF-1) is a chemokine that is thought to be associ ated with recruitment of EPCs [8]. Therefore, SDF-1 could induce differentiation and proliferation of endothelial cells along with its synergistic effect on VEGF on inducing neo-angiogenesis [9]. There exist a few literatures investigating the role of EPCs in the cAVMs, therefore, we did a systematic review to understand the molecular impact of EPCs in influencing the disease progression and vascular remodeling [10].

\section{Methods}

A systematic search of electronic databases which included "PubMed", "EMBASE", “Google Scholar", and "Science Direct" from January 1st, 1990 to May 31st, 2019. Different MeSH terms were searched which included, "Endothelial Progenitor Cells (EPCs)", "Arteriovenous Malformations", and "Stromal-cell derived factor-1". The studies investigating the role of EPCs in CAVMs in humans were 
included. Experimental studies on rats and AVM other than brain were excluded for our review. The data was extracted by one author

Results

Vasculogenesis

\begin{tabular}{|c|c|c|}
\hline Table 1: Different Immunohistochemical markers identified in patients with cerebral AVMs. \\
\hline Author Name & Total no. of cases (n) & $\begin{array}{c}\text { Immunohistochemical stain of AVM nidus } \\
\text { Gao P, et al. [1] }\end{array}$ \\
\hline CD133 + in the vessel wall \\
Takagi Y, et al. [10]
\end{tabular}

Immunohistochemical analysis revealed that stem cell marker CD133+ co-expressed with KDR was positive in the brain AVMs nidus specifically in the vessel wall. This co-expression revealed that EPCs might be associated with remodeling of the vascular wall in AVMs as indicated in (Table 1).

Furthermore, double immunohistochemistry revealed that SDF-1 positive signals were expressed strongly in smooth muscle of the artery and vessel endothelial cells. SDF-1 is the cellular source of CD31, $\alpha$-SMA, and CD-68. CD68+ signals were present mainly in the vessel wall and in the adjacent parenchymal tissue of the AVM nidus. There was a positive correlation between SDF1/CXCR1-pathway and VEGF- $\alpha$ or HIF-1 $\alpha(\mathrm{p}<0.05)$ [11].

\section{Neovascularization}

CD31+, CD34+, CD133+ have been associated with increased angiogenesis depending upon the increased stage of AVM $(p=0.004)$ [12]. They are expressed in the endothelium of the vessel wall.

\section{Discussion}

Cerebral arteriovenous malformations (cAVMs) are abnormal, tortuous, dilated and tangled group of blood vessels connecting artery to vein without a capillary bed [13]. Previous studies have revealed that there exists an active remodeling process and angiogenesis in cAVMs, leading to progressive change in the size of these malformations [14]. Therefore, the literature exists to identify the role of EPCs in active vascular remodeling of these cerebral AVMs [13-16].

EPCs are precursors of bone-marrow derived cells with the potential to differentiate into mature endothelial cells [17]. These cells have positive marker for stem cell CD133 [18], the hematopoietic marker CD34 [19], as well as endothelial cell markers [20]: VEGF-2, CD31, and/or VE-cadherin. The exact phenotype of EPCs is still unknown but the combination of endothelial and hematopoietic lineage markers has been characterized to identify the EPCs
(NF, and no restriction in language was applied for our search. Statistical analysis was not performed due to a few numbers of studies.
[17-20]. Physiological and pathological conditions which include, angiogenic stimulation, ischemia, trauma and inflammation leads to endogenous mobilization of EPCs from bone marrow to peripheral blood [21]. EPCs migrate accelerate neovascularization by migrating and localizing to the sites of active remodeling and vasculogenesis [21,22]. Elevated level of EPCs have been found in multiple cancers which include lung cancer, breast cancer, multiple myeloma, and early stages of infantile hemangioma [22,23]. In contrast, patients with diabetes mellitus and stroke have decreased level of EPCs compared with the control subjects $[23,24]$.

In addition, SDF-1 is a specific mediator of EPCs mobilization and is a chemokine that helps in migrating the EPCs from the peripheral blood to the target tissue [25]. Double-fluorescent study revealed that expression of SDF-1 is upregulated in the nidus of brain AVMs, which is strongly associated with vasculogenesis and remodeling [26]. AVMs are characterized by high-flow shunting, therefore, expression of these EPCs will lead to more efficient adaptive process in terms of increased number of endothelial cells mitigating the effect of high flow blood and decreasing the risk of rupture of the nidus $[1,2,17]$.

In summary, our systematic review highlighted the fact that in cerebral AVMs the activation of endothelial and stem cell markers leads to recruitment of EPCs that leads to abnormal vascular formation. However, further studies are needed to identify targeted therapy for these precursor cells in the management of patients with AVMs.

\section{References}

1. Gao P, Chen Y, Lawton MT, Barbaro NM, Yang GY, et al. (2010) Evidence of endothelial progenitor cells in the human brain and spinal cord arteriovenous malformations. Neurosurgery 67(4): 1029-1035.

2. Kim H, Marchuk DA, Pawlikowska L, Chen Y, Su H, et al. (2008) Genetic considerations relevant to intracranial hemorrhage and brain arteriovenous malformations. Acta Neurochir Suppl 105: 199-206. 
3. Chen Y, Zhu W, Bollen AW, Lawton MT, Barbaro NM, et al. (2008) Evidence of inflammatory cell involvement in brain arteriovenous malformations. Neurosurgery 62(6): 1340-1349.

4. Hashimoto T, Wu Y, Lawton MT, Yang GY, Barbaro NM, et al. (2005) Coexpression of angiogenic factors in brain arteriovenous malformations. Neurosurgery 56(5): 1058-1065.

5. Chen Y, Pawlikowska L, Yao JS, Shen F, Zhai W, et al. (2006) Interleukin-6 involvement in brain arteriovenous malformations. Ann Neurol 59(1) 72-80.

6. Kawamoto A, Losordo DW (2008) Endothelial progenitor cells for cardiovascular regeneration. Trends Cardiovasc Med 18(1): 33-37.

7. Urbich C, Dimmeler S (2004) Endothelial progenitor cells: characterization and role in vascular biology. Circ Res 95(4): 343-353.

8. Peled A, Petit I, Kollet O, Magid M, Ponomaryov T, et al. (1999) Dependence of human stem cell engraftment and repopulation of NOD/ SCID mice on CXCR4. Science 283(5403): 845-848.

9. Oberlin E, Amara A, Bachelerie F, Bessia C, Virelizier JL, et al. (1996) The CXC chemokine SDF-1 is the ligand for LESTR/fusin and prevents infection by T-cell-line-adapted HIV-1. Nature 382(6594): 833-835.

10. Takagi Y, Kikuta KI, Nozaki K, Hashimoto N (2010) Early regrowth of juvenile cerebral arteriovenous malformations: report of 3 cases and immunohistochemical analysis. World Neurosurgery 73(2): 100-107.

11. Lu L, Bischoff J, Mulliken JB, Bielenberg DR, Fishman SJ, et al. (2011) Increased endothelial progenitor cells and vasculogenic factors in higher-staged arteriovenous malformations. Plast Reconstr Surg 128(4): $260 \mathrm{e}-269 \mathrm{e}$

12. Wang L, Guo S, Zhang N, Tao Y, Zhang H et al. (2015) The role of SDF-1/ CXCR4 in the vasculogenesis and remodeling of cerebral arteriovenous malformation. Ther Clin Risk Manag 11: 1337-1344.

13. Koizumi T, Shiraishi T, Hagihara N, Tabuchi K, Hayashi T, et al. (2002) Expression of vascular endothelial growth factors and their receptors in and around intracranial arteriovenous malformations. Neurosurgery 50(1): 117-124.

14. Hashimoto T, Lawton MT, Wen G, Yang GY, Chaly T, et al. (2004) Gene microarray analysis of human brain arteriovenous malformations. Neurosurgery 54(2): 410-423.

15. Hashimoto T, Mesa Tejada R, Quick CM, Bollen AW, Joshi S, et al. (2001) Evidence of increased endothelial cell turnover in brain arteriovenous malformations. Neurosurgery 49(1): 124-131.
16. Hatva E, Jaaskelainen J, Hirvonen H, Alitalo K, Haltia M (1996) Tie endothelial cell-specific receptor tyrosine kinase is upregulated in the vasculature of arteriovenous malformations. J Neuropathol Exp Neurol 55(11): 1124-1133.

17. Khakoo AY, Finkel T (2005) Endothelial progenitor cells. Annu Rev Med 56: 79-101.

18. Rouhl RP, van Oostenbrugge RJ, Damoiseaux J, Cohen Tervaert JW, Lodder J (2008) Endothelial progenitor cell research in stroke: a potential shift in pathophysiological and therapeutical concepts. Stroke 39(7): 21582165.

19. Diller GP, van Eijl S, Okonko DO, Howard LS, Ali O, et al. (2008) Circulating endothelial progenitor cells in patients with Eisenmenger syndrome and idiopathic pulmonary arterial hypertension. Circulation 117(23): 30203030 .

20. Florek M, Haase M, Marzesco AM, Freund D, Ehninger G, et al. (2005) Prominin-1/CD133, a neural and hematopoietic stem cell marker, is expressed in adult human differentiated cells and certain types of kidney cancer. Cell Tissue Res 319(1): 15-26.

21. Corbeil D, Joester A, Fargeas CA, Jászai J, Garwood J, et al. (2009) Expression of distinct splice variants of the stem cell marker prominin-1 (CD133) in glial cells. Glia 57(8): 860-874.

22. Asahara T, Kalka C, Isner JM (2000) Stem cell therapy and gene transfer for regeneration. Gene Ther 7(6): 451-457.

23. Vasa M, Fichtlscherer S, Aicher A, Adler K, Urbich C, et al. (2001) Number and migratory activity of circulating endothelial progenitor cells inversely correlate with risk factors for coronary artery disease. Circ Res 89(1): E1-E7.

24. Liew A, Barry F, O’Brien T (2006) Endothelial progenitor cells: diagnostic and therapeutic considerations. Bioessays 28(3): 261-270.

25. Asahara T, Takahashi T, Masuda H, Kalka C, Chen D, et al. (1999) VEGF contributes to postnatal neovascularization by mobilizing bone marrowderived endothelial progenitor cells. EMBO J 18(14): 3964-3972.

26. Ceradini DJ, Kulkarni AR, Callaghan MJ, Tepper OM, Bastidas N, et al. (2004) Progenitor cell trafficking is regulated by hypoxic gradients through HIF-1 induction of SDF-1. Nat Med 10(8): 858-864. 